\title{
Corporate Image Cognition Influence Perceived Quality and Purchase Intention Empirical Research
}

\author{
Jing $\mathrm{Li}^{1}$, Jiang $\mathrm{Li}^{2}$, Yongbiao Zheng ${ }^{2}$ \\ ${ }^{1}$ Economics and Management School, Tianjin University of Technology and Education, Tianjin, China; ${ }^{2}$ Economics and Manage- \\ ment School, Beijing University of Posts and Telecommunications, Beijing, China. \\ Email: lijingjing@live.com, buptj1@yahoo.cn,
}

Received 2013

\begin{abstract}
Based on the theory of corporate image and perceived quality, we researched influence of consumers corporate image cognition on consumers perceived quality and purchase intention. We take the telecoms operator as practical example to do questionnaire survey and analyze the data with SPSS16.0 and structural equation model; the research results show that consumers' corporate image cognition directly and prominently affects perceived quality instead of consumer purchase intention; It also shows that in china marketing environment, the social image of corporate image has the greatest effect on consumer perceived quality, followed by staff image and marketing image.
\end{abstract}

Keywords: Corporate Image Cognition; Perceived Quality; Purchase Intention

\section{Introduction}

As the development of market economy and technology, the products of different enterprises have tiny difference at the physical attribute level, Consumers in purchasing behavior not only rely on the product price, function, quality and other traditional parameters to choose the consuming goods, When and where and in which way the products are produced, and the enterprise image and other factors have become the influencing factors of the customers' purchasing behavior. Enterprise began to pay more and more attention to build the enterprise image, through setting up the good enterprise image to influence consumers to its product evaluation to have identity attitude, which can eventually lead to the product of the enterprise's preferences and enhance purchase intention, and eventually to take the purchasing behavior.

The current literatures have less research for enterprise image on consumer product service quality perception influence, therefore, through the questionnaire survey we get a data and use structure equation model to analyze influence of enterprise image on perceived quality and purchase intention, which has provided guidance for enterprise marketing management.

\section{Literature Review}

\subsection{Definition and Formation of Corporate Image}

The Different scholars have different point of view for the definition of enterprise image. Nicolas indo (1992) consider that Enterprise image is combined of all aspects of the enterprise customers view, and it is determined by stimulation provided by the enterprise, the individual cognitive style and circumstance under which cognition has function. Bai Yongxiu(2001) hold the view that Enterprise image is a general impression a enterprise or a community remains in the public mind; it is the comprehensive reflection of behavior abilities of behavior subject. Based on association network memory model, KELLER (1993) puts forward enterprise image is the perception of consumer in memory of the cognitive through association with the brand. Kotler (1991) puts forward enterprise image is a group of perception, faith and idea held by one person to an enterprise.

Enterprise activities and its complexity have led cognitive elements of consumers for corporate image are very complex. Kato bond macro (1989) found that enterprise image including technology image, market image, future-oriented image, company atmosphere image, and operator image. Based on the correlation network memory model Brown\&Dacin (1997) divided consumer association into company ability association and the company society responsibility association. LeBlance, Gaston, Nguyen Nha (1996) found that the service enterprise image is formed by enterprise identity characteristics, enterprise reputation, service environment, service level and the service contact. Fombrun (2000) put forward enterprise image is formed by emotional appeal cognitive, 
product and service, vision and leadership, working environment, social and environmental responsibility, financial performance; he also designed 20 measuring project. This paper is based on the research of Fombrun's classification.

\subsection{Conception of Perceived Quality}

Quality research focuses on two aspects: one is based on the product or manufacturer's objective quality research, such as total quality management (TQM), according to external and internal properties of product including durability, safety, design, appearance and other predefined idealized technology standards enterprise and product quality experts take objective and impartial evaluation (Rieszm,1978; Zeithaml, 1988), on the other hand, based on consumer perception of quality research, some scholars put forward owing to information asymmetry consumers can't get and understand all technical index of quality evaluation, but according to relevant information they always can draw their own conclusions to judge the quality of the products, good or bad. It is the general abstract conclusion that determines the customer's choice of the products. In the evaluation of the quality of your product or service, consumers rarely adopt the objective quality of the products, but they always adopt the quality of the consumers perceive to judge the quality of your product or service (Gokdrick, 1984), Zeitham (1988) thinks that perceived quality is the overall superiority or remarkable judgment of consumer to the products. Based on cue utilization theory, Kirmani (2000)put forward perceived quality is all the advantages of evaluation of the brand consumers use internal and external clues. In the definition of perceived quality, Mitra and Golder (2006) introduced the conception of quality expected, that perceived quality comes from consumer oneself or others experience related to enterprise, marketing information, its form is not dependent on the use or inspection of the product.

\section{Study Method and Data Colleting}

\subsection{Propose Research Hypothesis}

According to the cue utilization theory, the cognition of enterprise image of consumer is one of important clues that influent consumer to judge the quality of service, especially when consumer faces new products, important information will be missing, consumers makes judgment in the available clues and lack product attributes. In the market at any time consumers will link company and products together; this is why many companies apply brand strategy. when people's product evaluation happens in situation full of company information, the company association will become the key framework of evaluation about the product (WangHaiZhong, 2006), Huang Heshui (2009) points out that with the real estate disputes increase, when buying a house consumers will take real estate developer into account, on the one hand, they try to find out the credit of the real estate developer, on the other hand they want to know company scale of real estate developer. Foreign scholars study the effects of all kinds of company association on consumer reflection, but the study conclusion are ambiguous, a study showed that the company image has positive influence on consumer product evaluation and performance (Belch, 1987; Carlson, 1963), but Hardy (1970) found that the negative relationship between company image and product preference, Shimp\&Bearden (1982) found the company image did not have a strong influence on consumer reaction.

So we propose the following research hypothesis:

H1: Corporate image cognition has effect on consumer perceived quality

$\mathrm{H} 2$ : consumer perceived quality has effect on consumer purchase intention

In the competitive global market, consumers begin caring about information about the company behind the product and brand (Philip J. The Kitchen, Andrew Laurence, 2003), good enterprise image can attract more consumers and increase confidence of customer for products and services, advertising content and purchase decisions (Fombrun, 1998; Lafferty\&Goldsmith, 1999), so we put forward:

H3: Corporate image cognition has effect on consumer purchase intention

\subsection{Variable Determination}

This research mainly involves three variables: enterprise image cognition, perceived quality and purchase intention. referring to the enterprise image measurement index and scale of Dodds (1991); Fombrun (2001); Cohen (1963); Manfred (2004) this study measured enterprise image cognition from the customer orientation, market performance, staff image, social responsibility, the development foreground, emotional appeal six aspects, designing a total of 16-item to measure it. We measured perceived quality from the overall evaluation, reliability, advanced three aspects of three questions. Integrating the measurement of purchase intention of Michael (1982), Dodds (1991), we measured purchase intention from three specific measurement items. All of the questionnaires use likerts' level 5 scale, from "much don't agree" to "much agreed to" give $1 \sim 5$ points score to measure.

\subsection{Data Collecting}

We chose the telecom enterprise brand and $3 \mathrm{G}$ service as the research object, at first we have a small scale research 
$(\mathrm{N}=50)$, and on the basis that we give necessary refining word modifying of our questionnaire to enhance the test ability of questionnaire. In formal investigation we give out 250 questionnaire with valid questionnaires for 236 copies, effective recovery rate is $94.4 \%$. telecom enterprise brand distribution for China Telecom, China Mobile, China Unicom $=1: 1: 1$, male accounted for, $61.9 \%$, female accounted for $38.1 \%$. From profession distribution: students $44.78 \%$, working people accounted for $55.22 \%$. From the age distribution : $<20$ years old $8.2 \%$, 20 to 30 years old (79.1\%), 31 to 40 to $10.4 \%, 41$ to 50 accounting for $2.2 \%$. Revenue: personal income $<1000$ yuan accounted for $31.3 \%$, and from 1000 to 2000 (20.1\%), and 2000 to $3000(18.7 \%)$, and $3000-4000$ (4.5\%), and 4000 to $50000.7 \%$, more than $500018.7 \%$.

\subsection{Data Analysis}

1) Analysis of reliability and effectiveness of the scale

Through the Cronbach's a coefficient and Item-to-Total related coefficient we test internal consistency and reliability of the scale. The preliminary reliability analysis showed that some components' Cronbach 's a coefficient is below 0.7 which is the critical value Nunnnally and Bernstein (1994) recommended, Item-to-Total correlation coefficient tests showed the subject further cuts can be measured in order to improve the Cronbach's a coefficient values. So we have exploratory factor analysis on measurement items of enterprise image and perceived quality, the results in Table 1. KMO statistics is 0.912 , Bartlett 's Test results are also significant, which suggests that it is meaningful to analyze the main component of the factor of enterprise image. Using SPSS16.0, take varimax orthogonal rotation method to carry on the factor rotating, and extracted features more than 1 of 3 root male factor, a total of $77.761 \%$ of the total variance explained. Factor analysis results see Table 1.

From Table 1 we can see the 16-item can be summed up in three main factors, according to the size of the loading of factor to name the three factors of. $\mathrm{F} 1 \mathrm{c} 12$-on the $\mathrm{c} 17$ loading are above $0.6, \mathrm{~F} 2$ in $\mathrm{c} 6-\mathrm{c} 9$ the loading above 0.8 , factor $\mathrm{F} 3$ in $\mathrm{c} 2, \mathrm{c} 4, \mathrm{c} 10 \mathrm{c} 11$ the loading are close to or greater than 0.7 , we can observe that $\mathrm{c} 2$ and c4 factor loading are not outstanding, therefore, we delete the $\mathrm{c} 3$ and $\mathrm{c} 5$-item. Combined with the meaning of each-item, we define the six involved in the variables hypothesis again, shrinking the scope of the market performance of the enterprise, eliminating the factor of enterprise research and development ability; Enterprise staff cognition image meaning has been widened; Telecommunication enterprise as a service type of enterprise, the quality of the service employees and concern for the customer will directly affect the development of the enterprise, so we have put the service of the personnel and focus on customer's complaint down to enterprise staff image cognition, that is we divide the enterprise image cognition into three dimensions: enterprise market performance image cognition, corporate social image cognition, the image of the enterprise staff cognition. After deleting the item Cronbach's a coefficient value range 0.88 to 0.9263 , higher than the critical value of 0.7 . Therefore, this research scale has good internal reliability.

Table 2 results indicate that comparing the three groups model, chi-square values exist significant differences, showing that limited model and not limited model are significantly different, so we can think that staff image and market image, staff image and social image, market image and social image of the difference between the two dimensions of the scale effect degree is high. In aggregate, enterprise image scale difference validity is high.

Table 1. Rotated component matrix ${ }^{\mathrm{a}}$.

\begin{tabular}{|c|c|c|c|}
\hline \multirow{2}{*}{ item } & \multicolumn{3}{|c|}{ Component } \\
\hline & 1 & 2 & 3 \\
\hline $\mathrm{c} 1$ & 0.167 & 0.409 & 0.695 \\
\hline $\mathrm{c} 2$ & 0.470 & 0.323 & 0.569 \\
\hline c3 & 0.256 & 0.234 & 0.811 \\
\hline $\mathrm{c} 4$ & 0.585 & 0.370 & 0.284 \\
\hline c5 & 0.263 & 0.831 & 0.195 \\
\hline c6 & 0.119 & 0.911 & 0.198 \\
\hline c7 & 0.149 & 0.852 & 0.249 \\
\hline $\mathrm{c} 8$ & 0.182 & 0.835 & 0.272 \\
\hline c9 & 0.403 & 0.199 & 0.735 \\
\hline $\mathrm{c} 10$ & 0.364 & 0.166 & 0.783 \\
\hline $\mathrm{c} 11$ & 0.842 & 0.146 & 0.211 \\
\hline $\mathrm{c} 12$ & 0.832 & 0.035 & 0.326 \\
\hline $\mathrm{c} 13$ & 0.869 & 0.053 & 0.250 \\
\hline $\mathrm{c} 14$ & 0.737 & 0.261 & 0.340 \\
\hline $\mathrm{c} 15$ & 0.774 & 0.252 & 0.278 \\
\hline $\mathrm{c} 16$ & 0.652 & 0.481 & 0.109 \\
\hline
\end{tabular}

Table 2. Discriminant validity of scale.

\begin{tabular}{cccccccc}
\hline Model & DF & CMIN & P & $\begin{array}{c}\text { NFI } \\
\text { Delta-1 }\end{array}$ & $\begin{array}{c}\text { IFI } \\
\text { Delta-2 }\end{array}$ & $\begin{array}{c}\text { RFI } \\
\text { rho-1 }\end{array}$ & $\begin{array}{c}\text { TLI } \\
\text { rho2 }\end{array}$ \\
\hline $\begin{array}{l}\text { Limited } \\
\text { model1 }\end{array}$ & 1 & 184.229 & 0.000 & 0.224 & 0.230 & 0.281 & 0.290 \\
$\begin{array}{l}\text { Limited } \\
\text { model2 }\end{array}$ & 1 & 130.523 & 0.000 & 0.122 & 0.122 & 0.126 & 0.150 \\
$\begin{array}{l}\text { Limited } \\
\text { model3 }\end{array}$ & 1 & 357.283 & 0.000 & 0.298 & 0.308 & 0.358 & 0.372 \\
\hline
\end{tabular}




\section{2) Hypothesis testing}

We put the survey data in Figure 1 model, using covariance modeling (AMOS method) to analyze integration model structure. We can judge that whole fitting degree of the model is better, see Table 3.

In fitting process, applying maximum likelihood estimation methods of its parameter estimation form path graph, from Figure 1 software analysis path can see the following information: the relationship between potential variables and the observed variables, the relationship between the latent variables and the latent variables, model path index, Index error term, index of factor in the loading results.
When creating variables relationship between staff image, market image, social responsibility image and purchase intention, model fitting degree didn't pass. When removing these relations, model fitting degree effect is good, indicating the assumption that enterprise image directly has positive influence on purchase intention is not correct. Table 4 lists the original hypothesis of model, standardization path coefficient, C.R. value and hypothesis testing results. In enterprise image dimensions social image has the biggest impact on the perceived quality, influence coefficient is 0.65 , followed by staff image, influence coefficient was 0.36 , and finally for market image 0.04 .

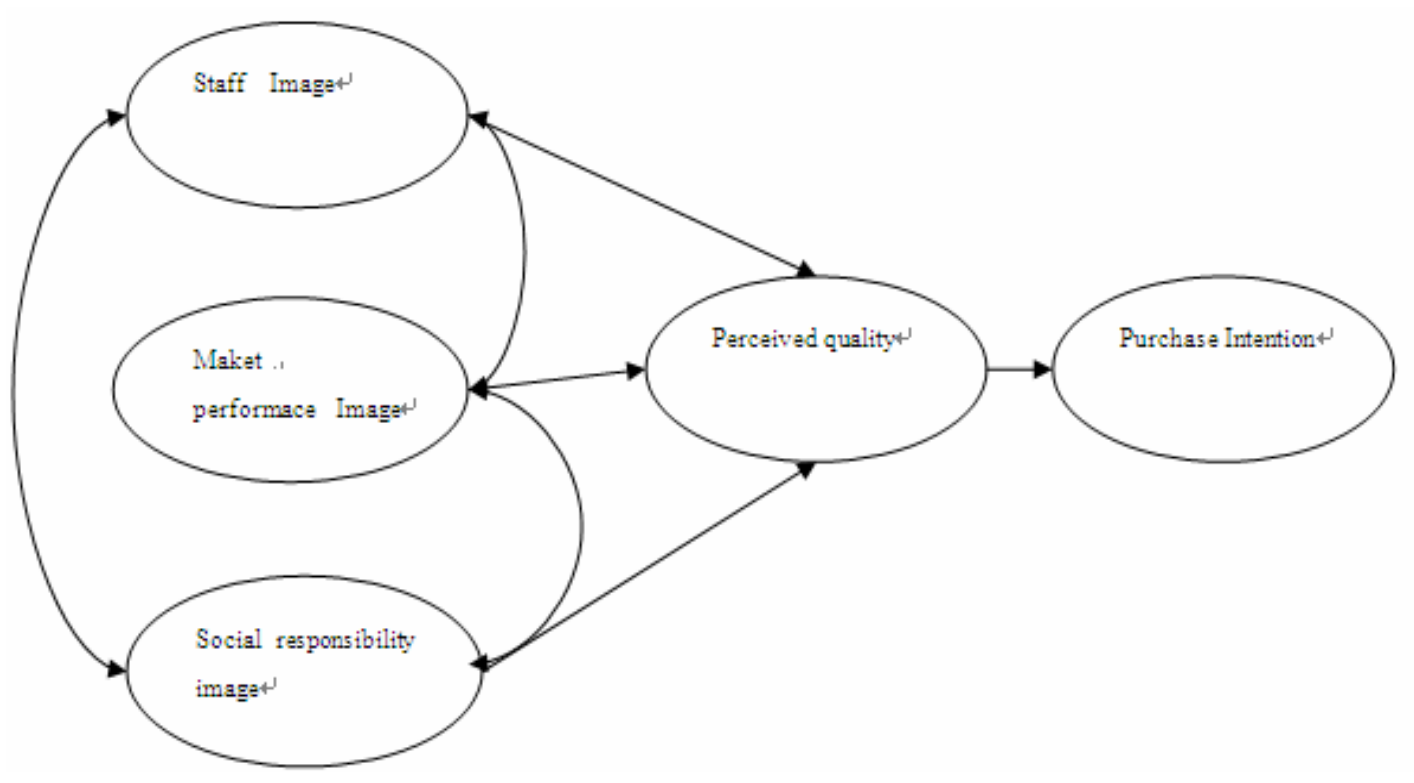

Figure 1. Stucture model.

Table 3. Model evaluation index.

\begin{tabular}{cccccccccc}
\hline \multirow{2}{*}{ FI } & \multicolumn{3}{c}{ Absolute fitting index } & \multicolumn{2}{c}{ Relative fitting index } & \multicolumn{2}{c}{ Brief fitting index } \\
\cline { 2 - 8 } & $\mathrm{X}^{2} / \mathrm{df}$ & GFI & RMSEA & NFI & IFI & CFI & PNFI & PCFI \\
\hline reference & $<2$ & $>0.90$ & $<0.06$ & $>0.90$ & $>0.90$ & $>0.90$ & $>0.50$ & $>0.50$ \\
Supposing model & 1.444 & 0.900 & 0.058 & 0.939 & 0.980 & 0.980 & 0.621 & 0.649 \\
\hline
\end{tabular}

Table 4. Standard path and hypothesis result.

\begin{tabular}{cccc}
\hline hypothesis & Standard path & C.R. & Hypothesis if pass \\
\hline H1a:staff I Image $\rightarrow$ perceived quality & 0.36 & 5.427 & Y \\
H1b:market image $\rightarrow$ perceived quality & 0.04 & 4.824 & Y \\
H1c:social image $\rightarrow$ perceived quality & 0.65 & 10.592 & Y \\
H2:perceived quality $->$ purchase intention & 0.59 & 8.385 & Y \\
\hline
\end{tabular}




\section{Conclusions}

The purpose of this study is to research the relationship between enterprise image cognition and consumers perceived quality, our research results confirm our hypothesis, (1) consumer enterprise image cognition influence the perceived quality and then further influence consumer purchase intention, (2) of the three dimensions of enterprise image cognition, social responsibility image has the greatest effect on consumer perceived quality, followed by staff image, and finally market performance. This study is different from that of the western scholars, western scholars study found that (Brown\&Dacin, 1997, 1994; KELLER\&Aaker Winters, 1998) enterprise social responsibility has little effect on product attributes perceptions, and companies ability cognition has a bigger impact on consumer products evaluation and have great effect on product quality cognition (3) perceived quality is a significant factor that influence customers' purchasing behavior.

Perceived quality is the important influencing factor of the consumer purchase intention. The enterprise can influence the perceived quality by improving the enterprise image. That whether an enterprise is worth trusting and has a sense of responsibility are also important factors influencing the perceived quality of the Chinese consumer. In China's cultural environment the consumer will not trust product or service of a brand if there is not a good enterprise as a support. As Chinese market environment and the company's regulatory system also need to be further perfected, all sorts of domestic enterprise crisis has made consumers not trust the brand enterprise as before, Chinese consumers will not obsessed with enterprise market performance and enterprise ability; an enterprise market performance is good, its product must be high quality as the only standard to judge; consumers pay more and more attention to the social responsibility of the enterprise image behind product. That whether the enterprise is honest and credible and whether has a real concern of consumer demand and participation in public welfare undertakings to reward the society plays a more and more important role in consumer judging the product quality. Managers can show that they are social concern and willing to social responsibility through charity, developing pollution-free product and providing equal employment opportunities. To the public, enterprise of wider social care may affect their judgment and evaluation of the enterprise.

This study only selected the telecom service providers 3 G service brand, and in real life different industry products are different, its consumer perception is different, and so the promoting significance of conclusion fell. Further research should be expanded to the selection of the industry, covering more categories of products, such as clothing, fast consuming goods and other brands of product category.

\section{REFERENCES}

[1] Y. X. Bai and H. Xu, "The Development of Small and Medium-sized Enterprises and Reputation Management," Economic Management, Vol. 8, 2001, pp. 20-21.

[2] Brucks, Merrie, V. A. Zeithaml and G. Naylor, "Price and Brand Name as Indicators of Quality Dimensions for Consumer Durables," Academy of Marketing Science, 2000, Vol. 28, No. 3, pp. 217-222. doi:10.1177/0092070300283005

[3] N. Bi, "An Experimental Research on the Impact of Cluster Branding Based on Product Perceived Quality," Management Review, 2009, Vol. 21, No. 5, pp. 23-26.

[4] T. J. Brown and A. D. Peter, "The Company and the Prodct: Corporate Associiations and Consumer Product Response," Journal of Marketing, 1997, Vol. 2, pp. 68-84. doi: $10.2307 / 1252190$

[5] R. O. Carlson, "The Nature of Corporate Images," In the Coporation and its Publics, John W. Riely, Jr., ed. New York: John,Wiley\&Sons, 1963, pp. 24-47

[6] W. B. Dodds, K. B. Monroe and D. Grewal, "Effects of Price, Brand, and Store Information on Buyers'product Evaluations," Journal of Marketing Research, Vol. 28, No. 3, 1991, pp. 307-319. doi:10.2307/3172866

[7] C. J. Fombrun, N. A. Gardberg and J. M. Sever, "The Reputation Quotient: A Multi-stakeholder Measure of Corporate Reputation," Journal of Grand Management, Vol. 7, No. 4, 2000, pp. 241-255

[8] D. A. Garvin, "Competing on the Eight Dimensions of Quality," Harvard Business Review, Vol. 65, No. 11, pp. 101- 112

[9] H. H. Huang, "Comparison of Strong and Weak of Brandassociation," Psychological Science, Vol. 5, 2002, p. 605.

[10] K. G. Hardy, "Whatever Happened to Image?" Business Quarterly, 1970, Vol. 35, pp. 70-76.

[11] K. L. Keller, "Conceptualizing, Measuring, and Managing Customer-Based Brand Equity," Journal of Marketing, 1993, Vol. 57, No. 1, pp. 1-22. doi:10.2307/1252054

[12] A. Kirmani and H. Baumgartner, "Reference Points Used in Quality and Value Judgements," Marketing Letters, Vol. 11, No. 4, 2000, pp. 299-310. doi:10.1023/A:1008129011202

[13] M. Schwaiger, "Components and Parameters of Corporate Reputation an Empirical Study," Schmalenbach Business Review: ZFBF, 2004, Vol. 56, pp. 46-72.

[14] D. Mitran, P. N. Golder, "How does Objective Quality Affect Perceived Quality? Short-Term Effects, Long-Term Effects, and As Asymmetries," Marketing Science, Vol. 25, No. 3, 2006, pp. 230-247. doi: $10.1287 / \mathrm{mksc} .1050 .0175$

[15] Nicolas indo. Corporate Image-Corporation Identefy Strategy, Guangdong : Tourism Press, 1992.

[16] C. P. Riesz, "Price Versus Quality in the Marketplace 
1961-1975," Journal of Retailing, 1978, Vol. 54, No. 4, pp. 15-28.

[17] A. Parasuraman, Zeithaml, A. Valarie and L. Berry, "L.SERVQUAL: A Multiple-Item Scale for Measuring Consumer Perceptions of Service Quality," Journal of
Retailing, 1988, Vol. 64, No. 1, pp. 12-40.

[18] H. Z. Wang, Brand Measurement and Promoting from Model to Implementation, Bei Jing: Tsinghua University press, 2006. 